\title{
Promoting Preservice STEM Education Teachers' Metacognitive Awareness: Professional Development Designed to Improve Teacher Metacognitive Awareness
}

\author{
Andrew John Hughes \& Eddie Partida
}

\begin{abstract}
This quantitative portion of a convergent complementarity, mixed-methods, exploratory study describes the design and implementation of a 5-week preservice teacher professional development (PD) experience and the associated Metacognitive Awareness Inventory (MAI) measures before and after the experience. The PD experience was designed to explicitly address participants' domain-general and domain-specific knowledge and regulation of cognition through a highly integrated academic and clinical preparation regimen centered on a cognitive coaching model. The study participants comprised preservice STEM education teachers $(N=11)$ enrolled in a dual teaching certification and Master's in Education program. The findings showed an increase in participants' regulation of cognition based on all utilized factor structures of metacognitive awareness, but not all factor structures indicated a change in participants' knowledge of cognition over the study period.
\end{abstract}

Keywords: metacognition, metacognitive awareness, professional development, preservice STEM education teachers, teacher preparation

Improving science, technology, engineering, and mathematics (STEM) education is a national priority (Parker et al., 2016). In recent years, STEM education in the United States has begun a transformation in response to concerns about there being a lack of needed focus on college and career readiness (Budget Act, 2013; National Research Council [NRC], 2012; NGSS Lead States, 2013). A Framework for K-12 Science Education: Practices, Crosscutting Concepts, and Core Ideas (Framework; NRC, 2012) put forth a vision for how science (and, arguably, engineering) education should be transformed. The Framework has since been operationalized through the development of the Next Generation Science Standards (NGSS). Despite the NGSS's focus on promoting inquiry-based teaching in science classrooms, preparing preservice STEM education teachers to deliver such ambitious

Hughes, A. J., \& Partida, E. (2020). Promoting preservice STEM education teachers' metacognitive awareness: Professional development designed to improve teacher metacognitive awareness. Journal of Technology Education, 32(1), 5-20. https://doi.org/10.21061/jte.v32i1.a.1 
instruction remains a major challenge for teacher preparation programs (Osborne, 2014; S. Wilson et al., 2015; S. M. Wilson, 2013).

There is a wide consensus that successful implementation of the Framework and the NGSS requires K-12 STEM educators to allow students to practice and apply the range of skills that scientists and engineers use when engaged in inquiry and problem solving (Kaderavek et al., 2015; NRC, 2012; Pratt, 2007). Yet, Osborne (2014) suggested that:

the goals of engaging in inquiry have been conflated with the goals of laboratory work such that, in the eyes of many teachers, the primary goal of engaging in inquiry is not to develop a deeper understanding of the whole process of inquiry but to provide a means of supporting their rhetorical task of persuading their students of the validity of the account of nature that they offer. (p. 178)

An inquiry and problem-solving approach will require a broad-spectrum change in K-12 STEM education, which necessitates that students and teachers develop a plethora of skills and abilities, including those under the metacognitive umbrella (Schraw et al., 2006; White et al., 2009). These metacognitive skills and abilities include knowledge of how (declarative), knowing that (procedural), and knowing why (conditional) as well as regulatory skills like asking questions, defining problems, planning, modeling, analyzing, interpreting, evaluating, and others (Osborne, 2014). Inquiry-based approaches to STEM teaching are inherently complex; therefore, teachers must have a sophisticated and coherent metacognitive skillset that often takes years to develop if they develop at all (Osborne, 2014; White et al., 2009). Preservice teacher preparation and in-service teacher professional development (PD) programs often do not focus on metacognition despite the evidence stating the importance of metacognition to both teaching and learning (Duffy, 2006). Teacher metacognitive awareness has become understood as a requirement given the complexity of teaching and learning inherent in inquiry-based STEM classrooms (Hughes, 2017; Osborne, 2014).

The power of the mind to think about and regulate one's own cognition is the key to both learning and teaching others (Pintrich, 2002; Saavedra \& Opfer, 2012). "High achieving students have been found to possess more metacognitive awareness and engage in more self-regulatory behavior than low achieving students" (Hartman, 2001a, p. 33). Georghiades (2004) and Gourgey (1998) argued that learning involving the application of metacognitive skills promotes deeper thinking, enhanced learning, and the ability to transfer learning into varying contexts. Metacognitive skills represent the synergy between knowledge and regulation of cognitive processes. Furthermore, metacognitive skills contribute to learning performance over and above intellectual ability (Schraw, 1998; Veenman et al., 2006). As suggested by Sternberg (1998), anyone still 
questioning "the importance of metacognition to student success need only" review the literature (p. 127). Georghiades (2004) indicated, using John Flavell's reasoning, that it was not a question of a student's ability to be metacognitive but rather a question of how a student was taught to be metacognitive.

Teachers play an important role in helping students develop metacognitive awareness (MA). The teachers' level of MA is a determining factor in their ability to promote students' MA (Kramarski \& Michalsky, 2009; Prytula, 2012; Pucheu, 2008). It can be inferred from the metacognitive literature (e.g., Georghiades, 2004; Gourgey, 1998; Hartman, 2001c) that teachers improve their teaching practices and student learning when they evaluate the interaction between student metacognitive functioning and other student attributes. Effective teaching entails: the knowledge of cognition necessary to create and sustain the type of environment that will improve student learning; the knowledge and selection of appropriate strategies, skills, and abilities based on varying situations; the knowledge of how, when, and why to adjust the difficulty of a given task based on each student's level of understanding; the knowledge to select and implement effective learning strategies; and the teacher's ability to use their knowledge of cognition to benefit students (Bransford et al., 2000; Hartman, 2001b; Lin et al., 2005; Schraw, 1998; N. S. Wilson \& Bai, 2010).

Additionally, effective teaching involves the regulation of cognition when teachers: plan, set goals, and allocate resources for instruction; organize the learning structure to promote cognitive restructuring based on the elaboration and summarization processes that ideally happen when students combine old and new information; monitor their own and their students' cognitive processes and strategy effectiveness; debug what did not work; and evaluate the effectiveness of their teaching practices and overall performance (Hartman, 2001b; Kramarski \& Michalsky, 2009; Lin et al., 2005). All of these identified skills needed for effective teaching are processes within a metacognitive framework.

\section{Professional Development}

The position that metacognitively aware teachers will have improved learning capability, teacher practices, and their ability to help students develop their MA has prompted interest in teacher preparation and PD programs specifically designed to enhance MA (Hughes, 2017; Prytula, 2012). To make the indicated teaching and learning improvements, these programs will need to focus on teaching with and for metacognition (Hartman, 2001c). Schools have started to add aspects of metacognition into teacher preparation and PD. Despite PD including some aspects of metacognition, recognized as metacognitive experiences, these aspects are often more of an add-on rather than a specific focus (Hughes, 2015). 
Exacerbating the problem of PD lacking a focus on MA is the indication that lower levels of MA are a reason that teachers are often apathetic about PD and are unable to transfer content from PD into effective classroom practices (Bransford et al., 2000; Hughes, 2017; Pucheu, 2008). Hughes (2017) indicated that teachers need MA or the PD needs to develop MA to help ensure active participation and completion of PD programs. Pucheu (2008) indicated that teachers require metacognitive capabilities to transfer material from PD training into effective classroom practices. Teachers' perspectives toward PD and their ability to transfer learning from PD training may be addressed by designing PD with a specific encompassing focus on improving levels of MA (Hughes, 2017).

PD is accepted to be vital for improving teacher effectiveness only when it is strategically planned based on the suggested characteristics of effective PD. "The term professional development (PD) refers to teachers' improvement or growth of skills and knowledge, primarily with the aim of improving student achievement (Guskey, 2003; Loucks-Horsley, Hewson, Love, \& Stiles, 1998)" (Hughes, 2017, p. 26). Suggested characteristics of effective PD include: strategic planning; challenging goals; adequate, flexible, and structured time; self-reflection; evaluation; feedback; collaboration; follow-up; continued support; and operational objectives leading towards long-term goals for improved student achievement (Hughes, 2015). Guskey (1991) identified that the process for instilling change in teachers made designing PD particularly complicated. Due to the complicated nature of designing PD and the overall complexity of the educational environment, it is difficult to identify precise elements that make PD effective (Guskey, 2003). However, the literature does describe characteristics that warrant consideration during the planning stages of PD programming. Mundry (2007) stressed that even without a consensus on characteristics of effective $\mathrm{PD}$, there is adequate knowledge about learning to "guide the design and implementation" of PD programs (p. 1).

\section{Characteristics of Effective Professional Development Practice}

The abundance of questions relating to the incorporation of certain characteristics deemed essential for effective PD can become onerous. Characteristics like adequate time for critical reflection, follow-up, knowledgebuilding, collaboration, and coaching from expert teachers can be challenging to implement but have had positive outcomes for science teachers (Mundry, 2007). The PD literature has increasingly identified various forms of coaching as an effective means to improve teaching practices. With the current educational climate of accountability and a recognized need to improve the teaching and learning of STEM, coaching was deemed an essential design attribute of the PD regimen.

Cognitive apprenticeship is a constructivist approach to coaching characterized by scaffolding assistance provided to a new teacher by a more experienced teacher with the aim of making tacit cognitive and metacognitive knowledge and processes explicit (Dennen \& Burner, 2008). Costa and 
Garmston (2002) expounded on coaching strategies in educational settings by defining "cognitive coaching" as a cyclical process designed to improve a teacher's instructional effectiveness by becoming more reflective about their teaching. Cognitive coaching has positive effects on teacher PD when implemented in collaborative settings characterized by high levels of interpersonal and organizational trust (Garmston et al., 1993; McLymont \& da Costa, 1998). Other positives include improvements in reflective practice, increased MA, and knowledge about and implementation of targeted instructional strategies (Batt, 2010; Bjerken, 2013).

\section{Developing Metacognitive Awareness}

The literature on metacognition addresses developing domain-general versus domain-specific MA. Schraw (1998) expressed "that cognitive skills tend to be encapsulated within domains or subject areas, whereas metacognitive skills span multiple domains" (p. 116). Although Schraw (1998) presented evidence to support his claim, Hartman (2001b) argued that cognitive and metacognitive skills are quite intertwined for students and teachers related to teaching and learning science. Schraw (1998) and Hartman (2001b) agreed on the relationship between metacognition and cognition only in the early stages of one's MA development.

The literature on MA also suggests the need to consider the complex, diverse, and malleable notions of metacognition (Hughes, 2019). That is to say, the MA literature defines a variety of constructs and noninclusive processes that underlie metacognition. These constructs are generally grouped into two broad categories: knowledge and regulation (or control) of cognition. If the goal is for a teacher to teach with and for metacognition, they will need to have: (1) an understanding of the importance of metacognition, (2) an awareness of their own and their students' metacognitive processes, (3) techniques to improve their own and their students' knowledge of cognition, (4) regulation of cognition, (5) an ability to foster an environment that promotes metacognitive development, and (6) the ability to implement domain-general (transferrable) and domain-specific MA development practices (Hartman, 2001b; Schraw, 1998).

There continues to be more discussion related to teachers' development of MA, mostly due to the evidence that a student's MA is related to their teachers' MA (Wilson \& Conyers, 2016; Wilson \& Bai, 2010). However, this discussion has been put to little action in preservice teacher preparation programs or inservice teacher PD (Duffy, 2006). Duffy (2006) indicated that teacher training tends to ignore the complexities of teaching; "Instead, the talk is about "teacher training,' which carries the implication that teaching is a mechanical matter of implementing technical acts in a predetermined manner" (p. 299). 


\section{Methodology}

The aim of this research study was to understand preservice STEM education teachers' development of MA through the context of PD specifically designed to improve MA. In this article, only the quantitative data analysis is presented. In subsequent publications, the results of qualitative data analysis, including observations, interviews, performance evaluations, focus-groups, and think-alouds, will be presented.

\section{Professional Development Program}

The 5-week PD was designed between late fall 2016 and summer 2017. The focus of the PD was improving teachers' ability to teach with and for metacognition. Metacognition was addressed during the PD in both domaingeneral and STEM-domain-specific knowledge and regulation of cognition. The PD was also designed around many of the suggested characteristics of effective PD, including explicitly communicating and implementing a strategic plan, positive expectations, and coaching and collaboration, which led to follow-up and continued support (Hughes, 2015). The PD had appropriately structured time that provided additional flexible time for the further development of metacognitive skills and inquiry-oriented teacher practices. There were two components to the PD: clinical and academic. The total combined time between the clinical and academic components was 160 hours -120 hours and 40 hours, respectfully.

The PD involved university professors, instructors, mentor teachers, and preservice STEM education teachers. For the clinical experience, university professors designed the curricular themes around which preservice teacher participants developed classroom materials. The two instructors were science and mathematics teachers with an average of 9 years of teaching experience in Grades 6-12 and about 3 years of teaching experience in teacher preparation programs. There were six mentor teachers with an average of 5 years of teaching experience in middle and high school science and mathematics. Together, the instructors and mentors worked collaboratively with the preservice teachers to develop their metacognitive skills and practices as well as inquiry-oriented STEM education teaching practices.

The PD approached and expressed teaching as a complex process that, when well-planned, still required fluidity with on-the-spot debugging and adjustment based on varying situations. The PD had closely linked clinical and academic experiences asking participants to operationalize learning into teaching practices. Furthermore, coaching was utilized as a part of the PD to increase participants' translation of carefully designed PD experiences into deeper knowledge as well as connecting this knowledge with effective classroom practices and metacognitive development (Kinnucan-Welsch, 2006).

Prior to the start of the PD, instructors and mentor teachers were extensively trained in: (a) coaching and, more specifically, cognitive coaching of preservice 
teachers, (b) MA, (c) teaching with and for metacognition, and (d) teaching metacognitively both generally and in the STEM domains. The cognitive coaching training included the use of a lesson plan facilitation guide, a formal teaching observation protocol, and a postlesson discussion guide. The MA training included defining related terms, learning the importance of MA, learning strategies to develop knowledge and regulation of cognition, creating environments that promote MA, the explicit modeling of thinking with both actions and verbally, and STEM-specific metacognitive strategies.

The clinical component of the PD involved participants teaching STEM enrichment classes to students in Grades 6-9 while under the tutelage of the instructors and university-selected, trained mentor teachers. The academic component involved study participants and mentor teachers attending biweekly methods-teaching seminars that were led by instructors. Both the clinical and academic components were specifically designed to help preservice teachers engage in cycles of planning, teaching, assessment, and reflection with emphasis placed on developing MA at each stage. Based on the already developed curriculum themes, preservice teachers were expected to develop and deliver daily lessons, assessments, and overall classroom experiences for students under the careful guidance and support of the mentors and instructors who continuously worked towards the strategic plan and goals by maintaining alignment between the clinical and academic components of the 5-week PD.

\section{Participants in the Professional Development Program}

The participants in this study were California preservice STEM education teachers working to obtain their preliminary mathematics or science teaching credential. All participants were expected to receive their preliminary, singlesubject credential shortly after completing a 15 -month Teacher Education Credential and Master of Arts in Education graduate program. The 5-week long PD program signified the first 2 months of the 15-month program. Shortly after completing the PD program, participants began teaching as either an intern or resident. Teachers with internships were hired by the school district and were considered the teacher of record for the courses taught. Teachers with residencies worked under the tutelage of a supervising teacher for an entire academic school year.

\section{Measuring Metacognitive Awareness}

For this study, the Metacognitive Awareness Inventory (MAI; Schraw \& Dennison, 1994) was used to collect pre- and post-treatment quantitative data on the participants' level of MA before and after the 5-week PD. The data was used to compare the participants' pre- and post-PD levels of MA in eight factor structures (Table 1). The MAI is a self-reported questionnaire with 52 items and, in this case, a fully labeled Likert-type scale. Metacognitive awareness consists of two main components, knowledge of cognition (KOC) and 
regulation of cognition (ROC). However, the MAI has had various composite structures based on multiple approaches to aggregating data, and this information is not always presented clearly (Harrison \& Vallin, 2018). MAI data has been aggregated into a single omnibus structure referred to as MA, various two-composite structures (usually either knowledge and regulation of cognition or Schraw and Dennison's (1994) exploratory two-factor structures), and eight-composite structures based on the subcomponents presented by Schraw and Dennison (1994).

Table 1

Factor Structures of Items on the Metacognitive Awareness Inventory

\begin{tabular}{|c|c|c|c|c|c|c|c|}
\hline $\begin{array}{c}\text { Meta- } \\
\text { cognitive } \\
\text { Awareness } \\
\end{array}$ & $\begin{array}{c}\text { Knowledge } \\
\text { of } \\
\text { Cognition }\end{array}$ & $\begin{array}{c}\text { Regulation } \\
\text { of } \\
\text { Cognition }\end{array}$ & $\begin{array}{c}\text { EFA } \\
\text { Factor } \\
1 \\
\end{array}$ & $\begin{array}{l}\text { EFA } \\
\text { Factor } \\
2 \\
\end{array}$ & $\begin{array}{c}\text { Uni- } \\
\text { dimensional } \\
\text { MRCML } \\
\text { model } \\
\end{array}$ & $\begin{array}{c}\text { KOC } \\
\text { MRCML } \\
\text { model } \\
\end{array}$ & $\begin{array}{c}\text { ROC } \\
\text { MRCML } \\
\text { model }\end{array}$ \\
\hline All 52 & $\begin{array}{c}3,5,10, \\
12,14,15, \\
16,17,18, \\
20,26,27, \\
29,32,33, \\
35,46\end{array}$ & $\begin{array}{l}1,2,4,6, \\
7,8,9,11, \\
13,19,21, \\
22,23,24, \\
25,28,30, \\
31,34,36, \\
37,38,39, \\
40,41,42, \\
43,44,45, \\
47,48,49, \\
50,51,52\end{array}$ & $\begin{array}{c}3,5, \\
7,9, \\
10, \\
12, \\
13, \\
15, \\
16, \\
17, \\
18, \\
20, \\
25, \\
26, \\
29, \\
30, \\
31, \\
32, \\
33, \\
39, \\
42, \\
45, \\
46, \\
51,52\end{array}$ & $\begin{array}{c}1,2, \\
4,6, \\
8,11, \\
14, \\
19, \\
21, \\
22, \\
23, \\
24, \\
27, \\
28, \\
34, \\
35, \\
36, \\
37, \\
38, \\
40, \\
41, \\
43, \\
44, \\
47, \\
48, \\
49,50\end{array}$ & $\begin{array}{c}6,8,10,16 \\
20,21,24 \\
26,27,32 \\
33,35,39 \\
40,41,43 \\
44,50,51\end{array}$ & $\begin{array}{l}10,16, \\
20,26, \\
27,32, \\
33,35\end{array}$ & $\begin{array}{c}6,8,21 \\
24,39 \\
40,41 \\
43,44 \\
50,51\end{array}$ \\
\hline
\end{tabular}

Note. $\mathrm{EFA}=$ exploratory factor analysis; $\mathrm{MRCML}=$ multidimensional random coefficients multinomial logit; $\mathrm{KOC}=$ knowledge of cognition; and $\mathrm{ROC}=$ regulation of cognition.

Each of these various structures has combined the 52 items from the MAI in different ways, sometimes based on exploratory factor analysis (EFA). Schraw and Dennison (1994) used EFA to produce two-factor structures with 
25 items moderately aligned with knowledge (Factor 1) and regulation (Factor 2) dimensions. Although more appropriate factor analysis exists (e.g., itemresponse theory [IRT] and confirmatory factor analysis [CFA]), researchers have continued to use EFA to examine the MAI's internal structure. Harrison and Vallin (2018) used the multidimensional random coefficients multinomial logit (MRCML) model to analyze the MAI while simultaneously using a CFA model. The use of MRCML and CFA identified items from the MAI that did not fit with the KOC and ROC dimensions, and those items were removed. The MRCML model's final reliability was .78 for knowledge and .82 for regulation dimensions (Harrison \& Vallin, 2018).

\section{Procedures}

The study began with Institutional Review Board (IRB) approval on June 6, 2017. In compliance with the IRB Human Subjects Committee guidelines, this study was conducted under the supervision and approval of the California State University of San Bernardino. The risks to subjects participating in the study were minimal and reasonable in relation to expected benefits. The PD program had a total of 11 preservice teachers, nine females and two males. After participants made an informed decision to participate, each was assigned a unique identifying number that was used to encrypt their pre- and post-PD MAI data. The participants were sent an email with a Qualtrics link to the MAI. The MAIs were completed and returned by participants both before starting and after finishing the PD experience.

\section{Data Analysis}

The analysis of the data began with entering of participants' self-reported values on the MAI into Statistical Package for the Social Sciences (SPSS). After entering the data, the assumptions of the Wilcoxon Sign Ranked Sum Test were checked and verified. The assumptions of dependent samples, random and independent data pairs, and ordinal-level measurement were easily verified. The assumption of homogeneity of variance required the use of the nonparametric Levene's test, which tested the null hypothesis that the variances were equal for each factor structure (see Table 2). The results indicated that the homogeneity assumption was valid for the MA data collected with the MAI.

Then, each participant's level of MA was determined by the mean of their responses to the items from each factor structure from the MAI (see Table 1). For example, each participant's awareness of their knowledge of cognition is the mean value calculated based on the participant's answers to the 17 items that correspond with the knowledge of cognition component. As indicated in Table 3 , the pre- and post-PD means of each participant's responses for each factor structure were compared using the nonparametric dependent samples Wilcoxon Sign Ranked Sum Test. 
Table 2

Nonparametric Levene's Test for Equality of Variances for Factor Structure of Data from the Metacognitive Awareness Inventory

\begin{tabular}{lcc}
\hline \multicolumn{1}{c}{ Factor Structure } & $F$-Statistic & $p$-value \\
\hline Metacognitive Awareness & .011 & .919 \\
Regulation of Cognition & .007 & .933 \\
Knowledge of Cognition & .015 & .904 \\
EFA Factor 1 & .026 & .873 \\
EFA Factor 2 & .024 & .878 \\
Uni-dimension MRCML model & .011 & .919 \\
KOC MRCML model & .002 & .961 \\
ROC MRCML model & .021 & .885 \\
\hline
\end{tabular}

Note. $\mathrm{EFA}=$ exploratory factor analysis; $\mathrm{MRCML}=$ multidimensional random coefficients multinomial logit; $\mathrm{KOC}=$ knowledge of cognition; and $\mathrm{ROC}=$ regulation of cognition.

Table 3

Comparison of Pre- and Post-Test Data Using Wilcoxon Sign Ranked Sum Test $(N=11)$

\begin{tabular}{|c|c|c|c|c|c|c|c|c|c|c|}
\hline \multirow[b]{2}{*}{ Factor Structure } & \multicolumn{2}{|c|}{ Mean } & \multicolumn{2}{|c|}{ Std. Dev. } & \multicolumn{2}{|c|}{ Min. } & \multicolumn{2}{|c|}{ Max. } & \multirow{2}{*}{\multicolumn{2}{|c|}{$\begin{array}{c}\text { Asymp. } \\
\text { Sig. } \\
\text { Z-stat. (two-tailed) }\end{array}$}} \\
\hline & Pre & Post & Pre & Post & Pre & Post & Pre & Post & & \\
\hline $\begin{array}{l}\text { Meta-cognitive } \\
\text { Awareness }\end{array}$ & 3.906 & 4.192 & 0.270 & 0.236 & 3.48 & 3.77 & 4.48 & 4.56 & -2.936 & 0.003 \\
\hline KOC & 4.107 & 4.380 & 0.281 & 0.246 & 3.76 & 4.06 & 4.76 & 4.71 & -2.404 & 0.016 \\
\hline$R O C$ & 3.808 & 4.101 & 0.315 & 0.265 & 3.34 & 3.54 & 4.34 & 4.49 & -2.937 & 0.003 \\
\hline EFA Factor 1 & 4.175 & 4.415 & 0.294 & 0.185 & 3.68 & 4.04 & 4.68 & 4.60 & -2.671 & 0.008 \\
\hline $\begin{array}{l}\text { EFA Factor } 2 \\
\text { Uni-dimension }\end{array}$ & 3.632 & 4.062 & 0.490 & 0.379 & 2.63 & 3.11 & 4.32 & 4.53 & -2.938 & 0.003 \\
\hline $\begin{array}{l}\text { MRCML model } \\
\text { KOC MRCML }\end{array}$ & 3.842 & 4.091 & 0.348 & 0.275 & 3.37 & 3.53 & 4.58 & 4.42 & -2.655 & 0.008 \\
\hline & 3.955 & 4.091 & 0.346 & 0.322 & 3.50 & 3.50 & 4.63 & 4.50 & -1.079 & 0.281 \\
\hline model & 3.755 & 4.109 & 0.528 & 0.327 & 2.60 & 3.30 & 4.50 & 4.40 & -2.586 & 0.010 \\
\hline
\end{tabular}




\section{Results}

The Wilcoxon Sign Ranked Sum Test was used to compare the participants' pre- and post-PD measurements on eight different factor structures. In Table 3, the asymptotic significance column illustrates that seven of the eight-factor structures were statistically significant at an alpha level of .05. The only factor structure that was not significant at an alpha of .05 was the knowledge of cognition MRCML model with a $p$-value of .281.

\section{Discussion}

The first finding from this study was expected: The results indicated that the preservice STEM education teacher participants increased their MA during the PD program. Hughes (2017) indicated that not only should the PD focus on MA, but the PD should focus on both MA development and utilizing characteristics of effective PD recommended from the literature. It is also suggested that higher levels of MA help participants translate academic experiences into clinical practices (Hughes, 2017; Pucheu, 2008). Relating students' learning needs to the teacher's ability to address those needs was also used to further invoke active participation. Although the PD experience was not designed to be self-regulated, as in Hughes (2017), it is similarly believed that MA development positively impacted participants' self-regulation and successful completion of the PD.

The second finding from this study is that the only MA factor structure from Table 3 without statistical significance was the knowledge of cognition MRCML model with a $p$-value .281. This suggests that the participants' reported knowledge of cognition on this factor structure was similar on both the pre- and post-PD measurement. While reflecting after an academic session, the university faculty, instructors, and mentor teachers noted participants' lack of knowledge related to cognitive strategies, skills, and abilities (declarative knowledge); use of strategies and techniques to improve learning (procedural knowledge); and when and why to use strategies (conditional knowledge). This anecdotal perceived lack in pedagogical content knowledge (PCK) and knowledge of cognition was represented in the quantitative data. Although knowledge of cognition and PCK was being covered throughout the PD, through reflection, it was determined that most of the time in the PD was focused on the regulation of cognition (planning, monitoring, organizing, information management, debugging, and evaluating). There were thorough discussions between the mentoring teachers, instructors, and faculty about the expected level of PCK and knowledge of cognition that a preservice teacher should possess. There was agreement that more time needed to be spent explicitly covering PCK and knowledge of cognition to ensure each preservice teacher participant's future success. 


\section{Conclusions}

The intent of this study was to assess the potential of a specific PD program to influence teachers' self-reported MA. Prior to collecting data, it was believed that the PD would lead to higher levels of MA. Based on the MAI data presented in this article, that would appear to be the case. Although this study does not portend to make causal claims about whether the change in participant's MA can be attributed to any particular design feature of the PD experience, this study offers a promising line of research currently absent in the literature on teacher PD in general and STEM education teacher preparation in particular. Future studies employing experimental or quasi-experimental approaches are needed to make such claims. Intuitively, it makes sense that MA would mediate the effect of a PD program on effectiveness, especially given the expansive role that MA plays in complex learning. Pursuing this line of inquiry would be a positive step towards linking PD to MA, content knowledge, and PCK development and, ultimately, laying a path forward for how to improve STEM education teacher effectiveness.

\section{References}

Batt, E. G. (2010). Cognitive coaching: A critical phase in professional development to implement sheltered instruction. Teaching and Teacher Education, 26(4), 997-1005. https://doi.org/10.1016/j.tate.2009.10.042

Bjerken, K. S. (2013). Building self-directed teachers: A case study of teachers' perspectives of the effects of cognitive coaching on professional practices (UMI No. 3564120) [Doctoral dissertation, Minnesota State University]. ProQuest Dissertations and Theses Global.

Bransford, J. D., Brown, A. L., \& Cocking, R. R. (Eds.). (2000). How people learn: Brain, mind, experience, and school (Expanded ed.). Washington, DC: National Academy Press. https://doi.org/10.17226/9853

Budget Act of 2013. California Legislature. Education Trailer Bill Assembly Bill 86, Chapter 48, (2013).

Costa, A. L., \& Garmston, R. J. (2002). Cognitive coaching: A foundation for renaissance schools (2nd ed.). Christopher-Gordon.

Dennen, V. P., \& Burner, K. J. (2008). The cognitive apprenticeship model in educational practice. In J. M. Spector, M. D. Merrill, J. van Merriënboer, \& M. P. Driscoll (Eds.), Handbook of research on educational communications and technology (3rd ed., pp. 425-439). Erlbaum.

Duffy, G. G. (2006). Developing metacognitive teachers: Visioning and the expert's changing role in teacher education and professional development. In S. Israel, C. C. Block, K. L. Bauserman, \& K. Kinnucan-Welsch (Eds.), Metacognition in literacy learning: Theory, assessment, instruction, and professional development (pp. 299-314). Erlbaum.

Garmston, R., Linder, C., \& Whitaker, J. (1993). Reflections on cognitive coaching. Educational Leadership, 51(2), 57-61. 
Georghiades, P. (2004). From the general to the situated: Three decades of metacognition. International Journal of Science Education, 26(3), 365-383. https://doi.org/10.1080/0950069032000119401

Gourgey, A. F. (1998). Metacognition in basic skills instruction. Instructional Science, 26(1-2), 81-96. https://doi.org/10.1023/A:1003092414893

Guskey, T. R. (1991). Enhancing the effectiveness of professional development programs. Journal of Educational and Psychological Consultation, 2(3), 239-247. https://doi.org/10.1207/s1532768xjepc0203_3

Guskey, T. R. (2003). What makes professional development effective? Phi Delta Kappan, 84(10), 748-750. https://doi.org/10.1177/003172170308401007

Harrison, G. M., \& Vallin, L. M. (2018). Evaluating the Metacognitive Awareness Inventory using empirical factor-structure evidence. Metacognition and Learning, 13(1), 15-38. https://doi.org/10.1007/s11409017-9176-z

Hartman, H. J. (2001a). Developing students' metacognitive knowledge and skills. In H. J. Hartman (Ed.), Metacognition in learning and instruction (pp. 33-68). Kluwer Academic. https://doi.org/10.1007/978-94-017-224383

Hartman, H. J. (2001b). Metacognition in science teaching and learning. In H. J. Hartman (Ed.), Metacognition in learning and instruction (pp. 173-201). Kluwer Academic. https://doi.org/10.1007/978-94-017-2243-8_9

Hartman, H. J. (2001c). Teaching metacognitively. In H. J. Hartman (Ed.), Metacognition in learning and instruction (pp. 149-172). Kluwer Academic. https://doi.org/10.1007/978-94-017-2243-8_8

Hughes, A. J. (2015). Impact of online self-regulated professional development on technology and engineering educators' metacognitive awareness (UMI No. 3710627) [Doctoral dissertation, North Carolina State University]. ProQuest Dissertations and Theses Global.

Hughes, A. J. (2017). Educational complexity and professional development: Teachers' need for metacognitive awareness. Journal of Technology Education, 29(1), 25-44. https://doi.org/10.21061/jte.v29i1.a.2

Hughes, A. J. (2019). Measuring metacognitive awareness: Applying multiple, triangulated, and mixed-methods approaches for an encompassing measure of metacognitive awareness. Journal of Technology Education, 30(2), 3-20. https://doi.org/10.21061/jte.v30i2.a.1

Kaderavek, J. N., North, T., Rotshtein, R., Dao, H., Liber, N., Milewski, G., Molitor, S. C., \& Czerniak, C. M. (2015). SCIIENCE: The creation and pilot implementation of an NGSS-based instrument to evaluate early childhood science teaching. Studies in Educational Evaluation, 45, 27-36. https://doi.org/10.1016/j.stueduc.2015.03.003 
Kinnucan-Welsch, K. (2006). Coaching for metacognitive instructional practice. In S. E. Israel, C. C. Block, K. L. Bauserman, \& K. Kinnucan-Welsch (Eds.), Metacognition in literacy learning: Theory, assessment, instruction, and professional development (pp. 373-389). Erlbaum.

Kramarski, B., \& Michalsky, T. (2009). Investigating preservice teachers' professional growth in self-regulated learning environments. Journal of Educational Psychology, 101(1), 161-175. https://doi.org/10.1037/a0013101

Lin, X., Schwartz, D. L., \& Hatano, G. (2005). Toward teachers' adaptive metacognition. Educational Psychologist, 40(4), 245-255. https://doi.org/10.1207/s15326985ep4004_6

McLymont, E. F., \& da Costa, J. L. (1998, April 13-17). Cognitive coaching the vehicle for professional development and teacher collaboration [Paper presentation]. American Educational Research Association, San Diego, CA.

Mundry, S. (2007, February 11-13). Professional development in science education: What works? [Paper presentation]. National Symposium on Professional Development for Engineering and Technology Education, Dallas, TX.

National Research Council. (2012). A framework for K-12 science education: Practices, crosscutting concepts, and core ideas. National Academies Press. https://doi.org/10.17226/13165

NGSS Lead States. (2013). Next generation science standards: For states, by states. National Academies Press. https://doi.org/10.17226/18290

Osborne, J. (2014). Teaching scientific practices: Meeting the challenge of change. Journal of Science Teacher Education, 25(2), 177-196. https://doi.org/10.1007/s10972-014-9384-1

Parker, C. E., Pillai, S. K., \& Roschelle, J. (2016). Next generation STEM learning for all: Envisioning advances based on NSF supported research. Education Development Center. https://www.sri.com/wpcontent/uploads/pdf/next_generation_stem.pdf

Pintrich, P. R. (2002). The role of metacognitive knowledge in learning, teaching, and assessing. Theory Into Practice, 41(4), 219-225. https://doi.org/10.1207/s15430421tip4104_3

Pratt, H. (2007). Science education's 'overlooked ingredient': Why the path to global competitiveness begins in elementary school. Education Week, 27(7), pp. 26, 32 . https://www.edweek.org/ew/articles/2007/10/10/07pratt.h27.html

Prytula, M. P. (2012). Teacher metacognition within the professional learning community. International Education Studies, 5(4), 112-121. https://doi.org/10.5539/ies.v5n4p112 
Pucheu, P. M. (2008). An investigation of the relationships between the Scoring Rubrics Inventory and the Metacognitive Awareness Inventory as reported by secondary school core-subject teachers (UMI No. 89145269) [Doctoral dissertation, University of New Orleans]. ProQuest Dissertations and Theses Global.

Saavedra, A. R., \& Opfer, V. D. (2012). Learning 21st-century skills requires 21st-century teaching. Phi Delta Kappan, 94(2), 8-13. https://doi.org/10.1177/003172171209400203

Schraw, G. (1998). Promoting general metacognitive awareness. Instructional Science, 26(1-2), 113-125. https://doi.org/10.1023/A:1003044231033

Schraw, G., Crippen, K. J., \& Hartley, K. (2006). Promoting self-regulation in science education: Metacognition as part of a broader perspective on learning. Research in Science Education, 36(1-2), 111-139. https://doi.org/10.1007/s11165-005-3917-8

Schraw, G., \& Dennison, R.S. (1994). Assessing metacognitive awareness. Contemporary Educational Psychology, 19(4), 460-475. https://doi.org/10.1006/ceps.1994.1033

Sternberg, R. J. (1998). Metacognition, abilities, and developing expertise: What makes an expert student? Instructional Science, 26(1-2), 127-140. https://doi.org/10.1023/A:1003096215103

Veenman, M. V. J., Van Hout-Wolters, B. H. A. M., \& Afflerbach, P. (2006). Metacognition and learning: Conceptual and methodological considerations. Metacognition and Learning, 1(1), 3-14. https://doi.org/10.1007/s11409006-6893-0

White, B., Frederiksen, J., \& Collins, A. (2009). The interplay of scientific inquiry and metacognition: More than a marriage of convenience. In D. J. Hacker, J. Dunlosky, \& A. C. Graesser (Eds.), Handbook of metacognition in education (pp. 175-205). Routledge.

Wilson, D., \& Conyers, M. (2016). Teaching students to drive their brains: Metacognitive strategies, activities, and lesson ideas. ASCD.

Wilson, N. S., \& Bai, H. (2010). The relationships and impact of teachers' metacognitive knowledge and pedagogical understandings of metacognition. Metacognition and Learning, 5(3), 269-288. https://doi.org/10.1007/s11409-010-9062-4

Wilson, S., Schweingruber, H., \& Nielsen, N. (Eds.). (2015). Science teachers' learning: Enhancing opportunities, creating supportive contexts. National Academies Press. https://doi.org/10.17226/21836

Wilson, S. M. (2013). Professional development for science teachers. Science, 340(6130), 310-313. https://doi.org/10.1126/science.1230725 


\section{About the Authors}

Andrew J. Hughes (andrew.hughes@csusb.edu) is Assistant Professor in the Career and Technical Education Program at California State University San Bernardino.

Eddie Partida (eddie.partida@cgu.edu) is Interim Director of the Teacher Education Department and STEM Coordinator in the Teacher Education Program at Claremont Graduate University. 